\title{
SOME REMARKS ON CASE RELATIONS
}

\author{
Jürgen Kunze
}

Zentralinstitut für Sprachwissenschaft

Akademie der Wissenschaften der DDR

Prenzlauer Promenade 149-152

Berlin

DDR-1100

\section{ABSTRACT}

The topic of the paper is the problem how to define case relations by semantic predicates. A general principle is outlined, which renders it possible to "calculate" case relations for a given representation of a (verb-) sememe by means of expressions. This principle is based on an assignment of case relations to primitive predicates and modification rules for nested expressions. Contrary to the traditional case grammar it turns out that one needs mixed case relations, especially for two reasons: Arguments occur at "too different" places in an expression or arguments iave combined case relations. The consequence is that case relations don't form a set of isolated elements but a strictured system.

1. Introduction

The paper is not intended for defending case relations in general. I want to sketcin only some problems connected with the definition of case relations and will demonstrate consequences, which seem partly a oit "unconventional".

I will not enter into the terminological discussion on deep cases, case relations etc. and subsume all these variants under the label "case relation". This is justified by the obvious fact that there are more proposals and systems than authors. So one will not overcome this chaos by neat terminological distinctions. It is rather typical for publications on deep cases that proposals are presented without sufficient motivation or justification (e. g. Nilsen 1973).

It has turned out that in the matter of case relations as a field of linguistic and fundamental research intuition and language competence cannot show the right way how to solve the problems of defining them. This is my first conclusion from the general scene. Without doubt it is inevitable to work out some principles on the basis of which case relations may be defined. This would eñable us

- to discuss a rather "clear" object (some principles instead of tens (or hundreds) of proposals),
- to evaluate and compare existing proposals,

- to connect case relations with other essential notions.

Quite another question is "What are case relations good for?". One cannot ignore the fact that a lot of serious objections against case relations have been advanced, covering a whole range from "they are redundant" till "the swamp of lacking plausible (or even formal) definitions" resulting in the conclusion that case relations are useless especially for computational linguistics (Mellema 1974, Luckhardt 1985). On the other hand many authors are advocates pro case relations, even in MT (e. g. Nagao 1986, Somers 1986). Here the character of case relations as a link (or pivot) is stressed between surface and deep level or between languages. For such situations one can akcept the use of case relations without exact definitions having an experimental system as a touchstone.

Case relations are considered here as names or labels of arguments in semantic predicates used for the description of (verb-) sememes. This is only one side of the coin! The second important aspect are the means by which deep cases are expressed at the surface (grammatical cases, prepositions, linear order, ....). They have to be taker into account as well, and only both aspects together will yield an adequate picture.

2. Case relations and semantic predicates

One possibility to grasp the whole problem seems to be the definition of case relations on the basis of semantic predicates. Sememes (of veri-lexemes) are represented by expressions containing primitive semantic predicates. The following expression may be assigned to a verb like "to convey": (a conveys b from c to d)

(1) $\operatorname{MOVE}-A C T I O N(a, b, c, d)$ $=A \operatorname{CAUSE}(a, \operatorname{CHANGE-POSITION}(b, c, d))$

(cf. Allen 1984). I will not discuss the question whether ACAUSE (= "agent causation") and CHAIGG-POSTTION are indeed 
primitive predicates. I consider them here as tinat. Furthermore one may discuss whetien (5) sufficiently describes the meaning of "to convey".

The iaea of extracting case relations from representations like (1) can be bases on the followine principles:

(A) For each primitive predicate $P$ there is an assignment of exactly one case relation to every aryument place : $z_{i}(P)=r_{i}$ ( $i-t h$ argument of $P$ has case relation $r_{1}$ )

(B) There are modification rules for case relations which render it possible to "calculate" the case relations for nested expressions.

(A) means e. 5 . that for a primitive predicate like CHANGE-POSITION $w$ know the case relations of the argument places $b$, $c$ and $d:$

(2) $z_{i}$ (CHANGE-POSITION) $=r_{i}$ for $1 \leqq i \leqq 3$ In this sense one can state without doubt

(3) $z_{1}$ (ACAUSE) = agent

(4) $z_{3}$ (CHANGE-POSITION) = goal

(B) may be interpreted in the following way: If we know

- ViOVE-ACIION has the form given in (1),

- tine value of $z_{2}$ (ACAUSE),

- seconi place of ACAUSE is filled in by CHAIGE-POSITION,

- the value of $z_{1}$ (CHANGE-POSITION),

then we know

- the value of $z_{2}$ (MOVE-ACTION), i. e. the case relation of $b$ in the whole expression (1).

Formally this may be expressed by a four-place "modification mapping" m:

(5) $z_{2}$ (MOVE-ACTION) =

m(ACAUSE, $z_{2}$ (ACAUSE), CHANGE-POSITION, $\mathrm{z}_{1}$ (CHANGE-POOSITION))

One may speculate whether all four arguments are indeed necessary, they are surely not. A similar idea is presented in Thiel 1982 ( $p .84 \mathrm{ff.}$ ), where the mechanism oí modification is applied, too.

A Eeneral scheme for (B) is the following: Assume one has

(6) $2(\ldots, x, \ldots)$

$$
=R(\ldots, \hat{s}(\ldots, x, \ldots), \ldots)
$$

where $x$ is the $j-$ th argument in $Q$, $S(\ldots)$ the $k$-th argument in $R$ and $x$ the 1 -th argument in $S$. Then $z_{j}(Q)$ is a function of $R, z_{k}(R), S$ and $z_{l}(S)$. Thiel's proposal, namely $z_{j}(Q)=m\left(R, z_{l}(S)\right)$, would cause some difficulties, if $R$ is a many place predicate and there are in $R$ arguments $S^{\prime}$ and $S^{\prime \prime}$ with $z_{l^{\prime}}\left(S^{\prime}\right)=z^{\prime \prime}\left(S^{\prime \prime}\right)$ (cf. the FEID-example below). Thiel himself excludes this case explicitely.

The principles (A) and (B) form a recursive scheme: (A) provides the results for certain predicates, (B) renders it possible to determine the results for (veri-) sememes in gentral.

At any rate one would get a nice formalisin for calculating case frames if (A) and (B) are fulfilled. Unfortinately, there are some additional problems J.' will deal with below. But at first I take an example:

(7) $\operatorname{SET}(a, b, c)$

$$
=\operatorname{ACAUSE}(a, \operatorname{BECONE}(\operatorname{STT}(b, c)))
$$

(8) $z_{2}(S I T)=$ locative

By a simplification of the general scheme (four-place function $m$ as in (5)) to the special variant one would obtain for $(7-8)$ :

(9) $z_{3}$ (SET)

$$
={ }^{3}(\text { ACAUSE, } m(\text { EECONE, locative)) }
$$

There are arguments for the assumption that BECOiE (and not ACAUSE) modifies locative to di cective (or goal): The description of "to get to a place" contains the expression

(10) $\operatorname{BECOKE}(3 \mathrm{E}(\mathrm{b}, \mathrm{c}))$ (as in (7))

Here one has the sane modification of locative to directive. Mris is in accordance witin Thiel 1982 .

Instead of (7) one colici take another expression, $\epsilon$. $g$. by usins the predicate ECAUSE (event causation) with the interpretation that "an activity of a causes BECONE(SIT $(0, c)) "$ :

(11) $\operatorname{SET}(a, 0, c)$ $=\operatorname{ECAUSE}(\operatorname{RCT}(a), \operatorname{BECONT}(\operatorname{SIT}(b, c)))$

Here the apolication of $(A)$ and $(B)$ is not quite the same, one has here instead of

(12) $z_{\uparrow}(\mathrm{SET})=z_{\uparrow}$ (ACAUSE) for $(7)$

a modification

$$
\text { (13) } \begin{aligned}
z_{1}(\operatorname{SET}) & =m\left(\text { ECAUSE, } z_{1}(\text { ACT })\right) \\
& =m(\text { ICAUSE, agentiv }) \\
& =\text { "causator" ? }
\end{aligned}
$$

These simple examples iilustrate some connectjons between the formal definition of case relations and semantic predicates.

\section{Expected complications}

Now I turn so some unpieasent questions that depress a oit the hope in this elegant suiution. Eut they are disagreeable oniy if one 
- maintains the principle "one instance per simple clause" for case relations (cf. Filimore 1968, Starosta 1981) and

- considers case relations as a rather small set without internal structure.

For a vero like "to swim" in a sentence. like "a swims fron b to $c$ " it is reasonable to assume a representation

(14) $\operatorname{SWIM(a)~\& ~CHAINGE-POSITION~}(a, b, c)$

What to do if in this example (or another of the same type) one detects that

(15) $\mathrm{z}_{1}$ (SWIM) $\neq \mathrm{z}_{1}$ (CHANGE-POSITION)?

Secondly, one needs new rules for hanaling an example like

(16) ASCERTAIN $(a, b)$

$$
=\operatorname{ACAUSE}(a, \operatorname{BECOME}(\operatorname{KIOW}(a, b)))
$$

where a appears twice and at two rather different places. One surely cannot assume that $z_{1}$ (ACAUSE) is the same relation as (17) $m\left(A C A L S E, m\left(B E C O M E, z_{1}\right.\right.$ (KNOW)))

if one makes the same simplification as for (7). Another question appears in

(18) $\operatorname{FEED}(a, b, c)=\operatorname{ACAUSE}(a, \operatorname{eAT}(b, c))$

This time one has two agents ( $a$ and $b$ ).

The next question is due to reflexive verbs. If we take German examples, we have e. g.

(19) Er wäscht sich $\neq$ Er wäscnt ihn as in English, too (himself $\neq$ him). Here the case relation of "Er" should be a mixture between agent and something like experiencer or patiens (cf. Thiel 1982, p. $104 \mathrm{f.}$ ). The second components may not be left out because of the reflexive verbs proper in German as "sich fürchten" (to be afraid, "sich schämen" (to be ashamed). Here the appropriate case relation is not agent: A "semantic paraphrase" for these verbs is "Etwas macht mich fürchten" (Somethin makes me afraid) etc. In my opinion there is no sharp boundary between the two types of reflexive verbs: Such a critical case is e. g. "sich aufresen" (to get excited).

The fifth question is connectea with "plastered up" case relations. It does not make sense to discuss whether one has in (20) either the case relation instrumental or locative (cf. Thiel 1982, p. 104 f.):

(20) I warmed the foot on the stove.

The same applies for temporal and causal relations in other examples.

4. Some conclusions

From the questions and lacking answers one may draw some conclusions:
I. If one defines case relations by means of semantic predicates as explained above, one needs in addition at least one of these two tinings:

- a two-place relation " $\leqq$ "within the set of case relations in order to compare them accoraing to their "specificness": For certain pairs of case relations $r_{1}, r_{2}$ one has then " $r_{1} \leqq r_{2}$ " with the meaning " $r$ 1 is equal to or more specific than $r_{2}$ " (cf. the SWIM example). In this sehse one may say that e. 5 . objective is "the sementical most neutral case" (Cook 1971), i. e. one could establish case relations that are more specific than the case relation objective.

- a two-place operation " - " for mixing case relations: For certain pairs of case relotions $r_{1}, r_{2}$ there is a case relation $r$ with $r=r_{1} \cdot r_{2}$ (cr. the example (20)).

So the set of all case relations becomes a structured system: Every case relation stands no loneer for itself alone.

II. One cannot derive case relations from semantic predicates without presupposing a synonyiny relation between sememes: If one assumes that the two sentences

(21) John sells Jin a car.

(22) Jin buys a car from Jorn.

are synonymous, $i . e$.

(23) $\operatorname{SEIL}(a, 0, c)$ and

(24) $\operatorname{BUY}(b, a, c)$

have the same representation, ther the case relations have to be the same:

(25) $\begin{aligned} z_{1}(\text { SEII })=z_{2}(\text { BUY }) & (\text { of } a) \\ z_{2}(\text { SEII })=z_{1}(\text { BUY }) & \text { (of b) }\end{aligned}$

If one admits that (21) and (22) are not synonymous one may have different case. relations.

This aspect is in a sesse indepencient of the approach proposed here: The same question may be put without reference to semantic predicates. One needs such a synonymy relation at any rate for case relations. Obviously the different intuitive use of the synonymy is one reason for the rather chaotic situation.

III. A aiscussion of $(23-24)$ and (18) shows furthermore that a relation or operation mentioned in $T$. provides the means for a distinction of different agents as John and Jim in $(21-22)$ or the two agents in (18): In the latter case $b$ is an "influenced agent". This has to be expressed precisely by the modification rules. 
Allen, J. F. 1984 Towards a General Theory of Action and Time. In: Artificial Intelligence 23: 123-154.

Cook, W. A. 1971 Improvements in Case Granmar. In: Language and Iinguists, Woricing Paper Nr. 2, Georgetown University, Washington D. C.

Fillmore, Ch. 1968 The case for case. In: Bach, E., Harms, R. T., Eds., Universais in Iinguistic Theory, Holt, Rinehart and Winston, New Yorik: $1-88$.

Fillmore, Ch. 1977 The case for case reopened. In: Cole, P., Sadock, J. M., Eds., Syntax and Semantics 8: Grammatical Relations, Academic Press, New York: 59-82.

Koch, W. 1978 Kasus - Kognition - Kausalität. Lunder germanistiscine forschunjen 47, CWK Gleerup, Iund.

Luckhardt, H.-D. 1985 Valenz und Tiefenkasus in aer maschinelien Ujersetzung. CL-Report No 4, Sonaerforscinungsbereich 100, Teilprojekt A2, Universität des Saarlandes, Saarbrücken.

Miellema, P. 1974 A Brief Against Case Gramar. In: Foundations of Ianfuage 11: $39-76$.

Nagao, M. 1986 Current Status anä Future Trends in Hachine Translation. In: Future Generations Computer Systems 2(1986): 77-82.

Nilsen, D. I. F. 1973 The Instrumental Case in English. Mouton, The Hague.

Somers, H. I. 1986 The need for WT-oriented versions of Case and Valency in MT. In: Proceedings COLING-86: 118-123.

Starosta, St. 1981 Die "1-Pro-Sent"-Lösung. In: Pleines, J. Ed., Beiträge zum Stand der Kasustheorie, Gunter Narr, Tübingen: 45-147.

Thiel, M. 1982 Zur Verwenaung der Kasusgramatik im faktenorientierten Information Retrieval von Textaaten. Spracie und Information, vol. 2, iviemeyer, Tübingen.

Address of the author:

Prof. Dr. Jürgen Kunze

ZI für Sprachwissenschaft der AdW der DDR Prenzlauer Promenade 149-152

Berlin

DDR -1100 